\title{
From What Might Have Been to What Must Have Been: Counterfactual Thinking Creates Meaning
}

\author{
Laura J. Kray and Linda G. George \\ University of California, Berkeley
}

\author{
Katie A. Liljenquist \\ Brigham Young University
}

Philip E. Tetlock

University of California, Berkeley

\author{
Adam D. Galinsky
Northwestern University \\ Neal J. Roese \\ University of Illinois at Urbana-Champaign
}

\begin{abstract}
Four experiments explored whether 2 uniquely human characteristics-counterfactual thinking (imagining alternatives to the past) and the fundamental drive to create meaning in life-are causally related. Rather than implying a random quality to life, the authors hypothesized and found that counterfactual thinking heightens the meaningfulness of key life experiences. Reflecting on alternative pathways to pivotal turning points even produced greater meaning than directly reflecting on the meaning of the event itself. Fate perceptions ("it was meant to be") and benefit-finding (recognition of positive consequences) were identified as independent causal links between counterfactual thinking and the construction of meaning. Through counterfactual reflection, the upsides to reality are identified, a belief in fate emerges, and ultimately more meaning is derived from important life events.
\end{abstract}

Keywords: counterfactual thinking, meaning, benefit-finding, fate perceptions, narrative identity

The quest for meaning has been a driving force throughout human history and an enduring concept in psychology (Baumeister, 1991; Bruner, 1990). Psychological well-being rests on an appreciation of how disparate experiences coalesce into coherence. Finding meaning in life events can reduce the burden of existential quandaries (Becker, 1971; Solomon, Greenberg, \& Pyszczynski, 1991) and improve health outcomes (Updegraff, Cohen Silver, \& Holman, 2008). From a developmental perspective, exploring regrets about past goals may foster richer and more complex forms of happiness (King \& Hicks, 2007). Discovering meaning amidst deprivation and sacrifice can also reaffirm the value of one's life (Bruner, 1991; Kurdek, 1999). Furthermore, the ability to derive meaning from personal tragedy and trauma is an essential component of effective coping (Frankl, 1963; Janoff-Bulman, 1992). For example, survivors' ability to find meaning in the September 11,

Laura J. Kray and Philip E. Tetlock, Department of Management of Organizations, University of California, Berkeley; Linda G. George, Department of Psychology, University of California, Berkeley; Katie A. Liljenquist, Department of Organizational Leadership and Strategy, Brigham Young University; Adam D. Galinsky, Department of Management of Organizations, Northwestern University; Neal J. Roese, Department of Marketing, University of Illinois at Urbana-Champaign. Neal J. Roese is now at the Department of Marketing, Northwestern University.

We thank the Dispute Resolution Center at Kellogg for financial support while conducting this research.

Correspondence concerning this article should be addressed to Laura J. Kray, 545 Student Services Building, \#1900 University of California, Berkeley, CA 94720-1900. E-mail: kray@ haas.berkeley.edu
2001, terrorist attacks predicted lower posttraumatic stress responses (Updegraff et al., 2008). Ultimately, amid rain or shine, the ability to find meaning in life is virtually a prerequisite for achieving the "good life" (King \& Napa, 1998).

The current research examines how counterfactual thinking, or reflection about "what might have been," aids in this universal quest for meaning (Galinsky, Liljenquist, Kray, \& Roese, 2005). We contend that, whether it be the thrilling first encounter with a future spouse or the tragic loss of a loved one, reflecting on and mentally undoing moments in which life was profoundly altered is critical for appreciating life transitions. In other words, asking "what would my life be like if this pivotal experience had not occurred?" facilitates understanding of the event's significance in the big picture of life. Although it might seem that counterfactual reflections could just as easily highlight life's arbitrariness, we propose an ironic relationship between the perceived mutability of life events and the sense that those events were destined and thus infused with underlying meaning. We predict that mentally constructing counterfactual worlds actually increases, rather than decreases, the perception that life's actual path was "meant to be," lending significance to these critical events. Reminding oneself that life could have turned out differently helps one not only to understand why events took one turn rather than another but also renders greater meaning to the turn that events did take.

We define meaning as the emergence of a personal narrative identity characterized by connectedness, purpose, and growth (McAdams, Reynolds, Lewis, Patten, \& Bowman, 2001; McGregor \& Little, 1998). Constructing stories about past events-why they occurred and what they led to-is important 
because it provides "causal, temporal, and thematic coherence to an overall sense of identity" (Singer, 2004, p. 442). By reflecting on how knowledge, relationships, and events from one's past are interrelated, personal meaning emerges (Leontiev, 2005).

By establishing a robust relationship between counterfactual reflection and meaning-making, we connect and contribute to a broad range of psychological literatures. For the first time, we demonstrate that counterfactual thoughts about one's life have predictable consequences for how critical events and cherished relationships are understood. By demonstrating that the effect of counterfactual reflection on the construction of meaning is partially driven by perceptions of fate's intervention, we also establish a critical link between an event perceived as "meant to be" and the self-defining significance derived from the event. We also demonstrate that when individuals reflect on a broad spectrum of personal turning points by considering aspects that are mutable, the actual outcome is viewed in a more positive light. By evoking a belief in fate and a more positive outlook of reality, counterfactual reflection appears to be a critical thread for mentally weaving a tapestry of meaning.

\section{Counterfactual Reflections on the Past}

Counterfactual thinking, which juxtaposes reality against a hypothetical universe, is an essential feature of healthy cognitive and social functioning and also a ubiquitous part of life (Summerville \& Roese, 2008). Disorders including Parkinson's disease and schizophrenia are marked, in part, by a diminished capacity to engage in counterfactual thought (McNamara, Durso, Brown, \& Lynch, 2003; Roese, Park, Smallman, \& Gibson, 2008). The pivotal role of counterfactual thinking in mental life is further evidenced by its impact on a range of affective, cognitive, and behavioral variables. In particular, counterfactual thinking, by illuminating what arguably should have been done in the past, serves many functions, including guiding and boosting subsequent performance (Epstude \& Roese, 2008; Kray, Galinsky, \& Markman, 2009; Roese, 1994, 1997).

Counterfactual thinking is often a driver of affective reactions, producing emotions ranging from regret (typically triggered by upward comparisons with better possible worlds) to relief (typically triggered by downward comparisons with worse possible worlds). The capacity to experience regret, an emotion uniquely derived from counterfactual thinking (Kahneman \& Miller, 1986), has been linked to complexity of thought and, ironically, even to happiness (King \& Hicks, 2007). In contrast, when the capacity to experience regret is limited by lesions in the orbitofrontal cortex, learning from experience is impaired (Camille et al., 2004). Spanning both ends of the emotional spectrum, counterfactual thinking can produce not only regret but also gratitude. Recent research has shown that mentally subtracting positive events from one's life can actually increase positive affective states (Koo, Algoe, Wilson, \& Gilbert, 2008) through a process akin to "counting one's blessings."

Regardless of whether counterfactuals highlight better or worse alternatives to reality, and independent of any ensuing emotional reactions, the process of thinking counterfactually helps to establish causal connections among otherwise discrete concepts (Einhorn \& Hogarth, 1986; Kray, Galinsky, \& Wong, 2006; Mandel, 2003; Mandel \& Lehman, 1996; Wells \& Gavanski, 1989). For example, in Kray et al.'s (2006) research, the sheer act of thinking counterfactually, regardless of whether individuals generated upward or downward counterfactuals about a target event, activated a relational processing style, characterized by a tendency to ponder associations and make connections between a set of stimuli and leading participants to perform better on a range of challenging analytic tasks that followed. For example, participants who engaged in counterfactual thought prior to completing the analytic section of the Law School Admission Test scored nearly 10\% higher than did participants under baseline conditions. Counterfactual thoughts are powerful tools for understanding how seemingly independent concepts and events are interconnected.

\section{From Counterfactual Reflection to the Construction of Meaning}

Our central hypothesis asserts that counterfactual thinking facilitates the construction of meaning. Undoing the past and considering alternatives ("what ifs") is a natural tendency when trying to figure out why things happened the way they did (Sanna \& Turley, 1996). Although such causal explorations can unleash regrets (Miller \& Taylor, 1995; Zeelenberg \& Pieters, 2007), we propose that constructing counterfactuals may instead increase the perception that life's actual path was meaningful, because the contrast underscores the opportunities, relationships, and achievements that would not have occurred without these key elements in one's life narrative. Just as counterfactual thoughts forge connections to create coherent solutions to problems, we expected that mentally undoing pivotal events would aid the construction of personal narratives. By illuminating the subsequent course of life's events, counterfactual reflection connects the dots and thereby makes the mutated events more meaningful and significant in one's history and life.

\section{Overview of Experiments}

We conducted four experiments to test our hypothesis that these two uniquely human characteristics - counterfactual thinking and personal meaning - are causally related. McAdams (2006) pinpointed the emerging adult years as the developmental onset of an internalized and dynamic story of one's life. Accordingly, in the current research, we explored the connection between counterfactual thinking and the construction of personal meaning among college students. Experiments 1 and 2 sought to establish a direct path from counterfactual reflection to perceptions of meaning in life decisions and relationships. Experiment 3 was designed to demonstrate that counterfactual reflection increases perceptions that life events and transitions are meant to be. Experiment 4 examined whether perceptions of fate and the identification of positive consequences mediate the impact of counterfactuals on life meaning. We also examined whether counterfactual reflection can produce more meaning than considering the meaning of the event itself. We expected that, through counterfactual reflection, the role of fate and the recognition of positive benefits from life transitions would crystallize, causing more meaning to be derived. Across the four experiments, we explored a range of life choices and events that varied in affective valence, seeking to establish a robust link between counterfactual reflection and the discovery of meaning. The overarching hypothesis posits that mentally subtract- 
ing events from one's life helps make those events even more meaningful, significant parts of one's life.

\section{Experiment 1: Counterfactuals and Meaning in College Choices}

Our first experiment tested the hypothesis that constructing counterfactual worlds for an event enhances the meaningfulness of the event in one's life. We asked half of the participants to consider how their decision to attend a particular college could have turned out differently. We predicted that, relative to control participants, these participants would find their college choice to be more significant and self-defining.

\section{Method}

Participants and design. The sample was composed of 32 (five male, 15 female, 12 information unavailable; two African American, nine Asian, six Caucasian, one Hispanic, two "other," 12 information unavailable) undergraduates. Participants received $\$ 10$ payment. The experiment included two between-subject conditions: counterfactual and baseline.

Procedure. Upon arrival at the laboratory, all participants wrote a short essay about why they ended up at their current university. Specifically, they were instructed to "Think about how you decided where to go to college. How did you end up coming to Northwestern? Looking back, list the broad sequence of things that led to your decision."

After completing the essay, half of the participants engaged in counterfactual thinking: "Describe all the ways that things could have turned out differently." The other half of the participants, comprising the baseline condition, did not receive this prompt and proceeded to the meaning questionnaire.

To assess how meaningful participants' choice of college was to their life, we used three items $(\alpha=.68)$ : "My decision to come to Northwestern defines who I am," "Coming to Northwestern has added meaning to my life," and "My decision to come to Northwestern was one of the most significant choices of my life." The response scale ranged from 1 (not at all) to 7 (extremely). After completing all measures, participants were paid and debriefed.

\section{Results and Discussion}

Participants who had considered counterfactual alternatives reported that their college choice was more meaningful and significant $(M=5.49, S D=0.82)$ than did those in the control condition $(M=4.73, S D=1.11), t(30)=2.21, p=.04, d=0.81$. Imagining the consequences of having chosen a different path caused participants to endorse more strongly the view that their ultimate college choice was a defining moment in their life.

\section{Experiment 2: Counterfactuals and Meaning in Personal Relationships}

This experiment explored whether counterfactual thoughts impart greater meaning to relationships as well. Koo et al. (2008) recently demonstrated that mentally subtracting a long-term romantic partner from one's life increases satisfaction with the relationship. In the current research, we sought to broaden our understanding of the impact of counterfactual thought on how relationships are perceived by looking beyond romantic relationships to friendships in general. Further, rather than focusing on relationship satisfaction, we measured the meaning that the relationship imparted to the individual's life. We also coded participants' essays to assess the relationship between counterfactual thought generation and meaning.

Experiment 2 was also designed to rule out an alternative explanation of the previous study's findings. Because the counterfactual manipulation required more elaboration than the baseline condition, it is possible that the effect of counterfactuals on meaning was due to the greater cognitive demands of the counterfactual task. In addition, only the counterfactual condition required participants to contemplate the consequences of their decision; hence, the results could be based more on focusing on consequences than counterfactual possibilities per se. To rule out both alternatives, we included in the current experiment a factual condition that directed participants to elaborate on the specific details and consequences of meeting a significant individual in their life.

\section{Method}

Participants and design. Participants were 38 (24 male, 13 female, one unclassified; three Asian, 32 Caucasian, two Hispanic, one "other") undergraduates who received $\$ 10$ payments. The experiment included two between-subjects conditions: counterfactual and factual.

Procedure. All participants were asked to write a short essay recounting how they met a close friend: "Think about a close friend of yours. How did the two of you meet? Looking back, please describe the various factors and sequence of events or circumstances that led to your meeting."

Next, participants in the counterfactual condition were instructed to "describe all the possible ways that you might not have met this person and how things could have turned out differently." Those in the factual condition were prompted to "describe any other details about the way you met that determined how things ultimately turned out." The two tasks were designed to be comparable in cognitive demand and consequential thinking.

Meaning measure. We used the same three-item meaning scale from Experiment $1(\alpha=.84)$, rephrasing it simply to refer to their chosen relationship rather than their college choice. The response scale ranged from 1 (not at all) to 11 (most definitely).

Essay coding. After counting the number of distinct thoughts expressed in each essay, two independent judges coded the number of thoughts that were counterfactual in nature, as well as their direction. Statements indicating how they would be better off were coded as upward (e.g., "I might not have spent so much time hanging out with him and done better in my classes"), statements indicating how they would be worse off were coded as downward (e.g., "I would have missed out on having an incredible friend during my life and especially my teenage years"), and statements that differed from the current reality but were not clearly better or worse were coded as neutral (e.g., "I might have met some other friends"). Reliability was high between coders ( $\kappa=.85, p<.001)$.

\section{Results and Discussion}

Counterfactual reflection $(M=8.35, S D=1.98)$ led the relationship to be seen as more meaningful and self-defining than did 
factual reflection $(M=6.80, S D=2.57), t(39)=2.12, p=.04$, $d=0.68$. Although close friends are by definition special, recognizing the contingencies underlying the relationship accentuated that relationship's significance.

Essay coding. The number of thoughts generated between the counterfactual $(M=3.93, S D=2.02)$ and factual conditions $(M=$ 3.27, $S D=2.33$ ) did not significantly differ, $t(35)=0.89, p=.38$, $d=0.30$. However, participants in the counterfactual condition $(M=3.60, S D=1.88)$ generated significantly more counterfactual statements than participants in the factual condition $(M=$ $0.14, S D=0.47), t(35)=8.31, p<.001, d=2.53$. This is not surprising, given that participants were instructed to mentally subtract a valued relationship from their lives, counterfactual statements were exclusively downward $(63 \%)$ or neutral $(37 \%)$ in valence. Meaning was significantly related to downward counterfactual generation, $r(37)=.33, p=.05$, but not neutral counterfactual generation, $r(37)=.18, p=.29$.

Counterfactual reflection endows both major life experiences and relationships with greater meaning. In combination with Koo et al.'s (2008) recent finding that mentally subtracting a significant other from one's life increases satisfaction with the relationship, the current research suggests that counterfactual reflection enhances the significance and value of both friendships and romantic partnerships. By identifying ways in which their lives would be worse without the existence of a focal relationship, participants imbued the relationship with meaning.

\section{Experiment 3: From What Might Have Been to What Was Meant to Be}

The previous experiments focused on two specific and generally positive life experiences: educational choices and personal relationships. In our next two experiments, we sought to generalize our findings by allowing participants to select turning points, or welldefined moments of transition after which a person's life is fundamentally altered (McAdams, 2001). McAdams, Josselson, and Lieblich (2001) analyzed life narratives and found that interpretations of major life transitions predict coping effectiveness and optimism about the future in part by helping to define one's identity. With or without tragedy, making sense of critical transitions in life anchors people's understanding of who they are. Indeed Giddens (1991) has argued that the core of a person's identity derives from the capacity to "keep a particular narrative going" (p. 54), to develop a sense of continuity across time and place. Turning points epitomize metaphorical forks in the road, moments at which counterfactual worlds should seem most plausible and vivid. As such, they are ideal for examining whether mentally walking down an untaken path erodes or solidifies meaning.

In addition to broadening the focal event, our third experiment examined a potential avenue through which counterfactual reflection inspires meaning. Envisioning alternative worlds might seem to highlight the randomness or capriciousness of life. However, we hypothesized that counterfactual thoughts would strengthen beliefs that pivotal moments in the past were meant to be or fated, which assumes a predestined path that could not have occurred any other way (Burrus \& Roese, 2006; Young \& Morris, 2004). We hypothesized a relationship between counterfactuals and fate for two reasons. First, counterfactual thinking can bolster the sense that "I knew it all along" and increase the hindsight bias (Nestler \& von Collani, 2008; Roese \& Maniar, 1997; Roese \& Olson, 1996). For example, if a sports fan easily generates a counterfactual that underscores a causal inference (e.g., "If only we had been playing on our home field, our team would have won"), the fan may believe the game's outcome was more inevitable in hindsight. Thus, a satisfying causal explanation can also increase a sense of inevitability about the outcome.

Second, counterfactual thinking may paradoxically encourage fate-based explanations for an event when the vast number of potential alternatives renders a single outcome statistically improbable. Consider the example of picking the winning lottery ticket (Landman \& Petty, 2000). As winners consider the endless numbers that they could have picked but did not, the fact that they did pick the winning numbers-defying the million-to-one oddsmakes their win seem all the more fated. Odd though it sounds, highlighting the improbability of an event bestows inevitability on the event. The logic appears to be: "Something so improbable could not have possibly happened by chance alone. Therefore, it must have been fated." When this sense of fate is augmented by the value derived from the sheer uniqueness of the event (Dai, Wertenbroch, \& Brendl, 2008; King, Hicks, \& Abdelkhalik, in press), it is even more likely to translate into meaning. We expected that counterfactual thought, pondering what reality would be like if a life-altering event had not redirected one's life, would enhance the sense that the turning point was "meant to be."

We hypothesized that perceiving fate as a driving force behind key life events will contribute to a sense of meaning. Consistent with the redemption themes prevalent in the life narratives of highly generative adults, for whom destiny may intervene to transform bad into good or weakness into strength (McAdams, 2006), fate perceptions are a useful device for creating a meaningful life narrative. The connection between fate and meaning may also be fortified to the extent that fate is employed in comprehending events in one's life that appear to defy material explanation (Pepitone \& Saffiotti, 1997). To test the hypothesis that counterfactual thinking enhances fate perceptions, we had participants identify a turning point in their lives and then varied how they reflected on the transition before measuring how fated they believed the event to be.

\section{Method}

Participants and design. Forty-two participants (20 men and 22 women) completed the questionnaire. The mean age of the sample was 21.5 years $(S D=4.2)$. Of the 42 participants, one (2\%; female) identified herself as Black or African American, 25 (60\%; 13 male, 12 female) identified themselves as Asian or Asian American, five (12\%; two female, three male) identified themselves as Hispanic or Latino, and 11 (26\%; seven female, four male) identified themselves as White. Participants received course credit for their participation. We randomly assigned participants to either the counterfactual or factual condition.

Procedure. Before receiving the experimental manipulation, participants were asked to identify a turning point in their life, which was defined by McAdams (2001) as follows: "Turning points are not very common moments or episodes in a person's life in which rapid, intense, and clear change occurs, such that the person and his or her life is never the same again. Turning points 
can be initiated by a person or from forces outside of the individual." To ensure that participants did not select a particular turning point based on their reflection condition, we had all participants identify a turning point by describing it in a sentence before turning the booklet page to the reflection instructions.

Participants in the counterfactual condition were asked to "Describe how your life would be now if the turning point incident had never occurred. Please write about who you would be, where you might be, the relationships you might have, the beliefs, values and feelings that might characterize you, or any other details about this alternate world that you can imagine." Participants in the factual condition were instructed to "Describe exactly what happened, when it happened, who was involved, what you were thinking and feeling, what happened right before and right after the incident occurred, or any other factual aspects of the incident that you can recall." 1

Next, participants reported the extent to which the turning point was a product of fate. The response scale ranged from 1 (not at all) to 9 (extremely).

\section{Results and Discussion}

Counterfactual reflection $(M=5.77, S D=2.33)$ increased the perception that the turning point was fated relative to factual reflection $(M=4.25, S D=2.45), t(40)=2.07, p=.05, d=0.64$. Thinking counterfactually about a critical juncture in one's life enhanced perceptions that it was meant to be. Rather than leading one to conclude that life could have easily unfolded differently, it appears that the act of mentally undoing a turning point enhanced the perception that fate drove its occurrence.

\section{Experiment 4: Fate and Benefit-Finding Mediate the Link Between Counterfactual Thinking and Meaning}

The previous experiment demonstrated that counterfactual thinking about a personal turning point enhances perceptions of fate, or that an event was meant to be. The current experiment takes this exploration further by connecting fate perceptions to the creation of meaning in life narratives. In considering why fate might enhance personal meaning, we focused on whether fate might satisfy a desire to make sense of pivotal events (Davis, Nolen-Hoeksema, \& Larson, 1998; Janoff-Bulman \& Frantz, 1997; Saffrey, Summerville, \& Roese, 2008). We contend that endorsing fate, whether attributed to deity or destiny, provides a rationale for why events unfolded as they did: They were meant to be. When counterfactual worlds are considered, invoking the hand of fate amounts to rejecting that counterfactual world as somehow not "fitting" one's evolving life narrative and instead embracing life as it is. When people believe their lives are as they were meant to be, they experience the gratification of being on the "right" course and fulfilling their life's mission. This ultimately injects the reality of how events actually unfolded with a heightened sense of meaning.

In addition to fate perceptions, the meaning-making process also endows life with significance (Davis et al., 1998; Janoff-Bulman \& Frantz, 1997), ranging from the discovery of positive outcomes to the realization of what really matters (Lehman et al., 1993; Miles \& Crandall, 1983; Taylor, 1983, 1989; Taylor, Kemeny, Reed, Bower, \& Gruenewald, 2000; Tedeschi \& Calhoun, 1996). In the current experiment, we explored the possibility that benefitfinding, or the recognition of positive consequences, serves as another mediator, operating independently of or in concert with fate perceptions. We expected counterfactual reflection to facilitate benefit-finding by underscoring the opportunities, relationships, and achievements emerging from transitions, for positive, neutral, and negative events alike.

Experiment 4 also tested an alternative explanation for why counterfactual thinking enhanced fate perceptions in the previous experiment. Burrus and Roese (2006) recently observed that abstract ("why") construals of past accomplishments enhanced fate perceptions relative to concrete ("how") construals (cf. Trope \& Liberman, 2003). This finding raises the possibility that counterfactual thinking enhanced fate perceptions in the previous experiment because it demanded a more abstract construal level than the factual thinking condition: When contrasting reality with what might have been, individuals may be more prone to consider why achievements and relationships occurred in the first place. To address this issue, we added a condition in which participants directly elaborated on the meaning of the turning point, which we expected to require an amount of abstraction similar to the counterfactual condition. If counterfactual reflection produces more meaning than directly reflecting on the meaning of an event, then it suggests counterfactual reflection operates over and above a construal-level effect.

The inclusion of a meaning condition also provided a conservative test of the hypothesis that counterfactual reflection serves a singular role in the construction of meaning. Introspective access to cognitive processes is often limited (Nisbett \& Wilson, 1977), and direct attempts at introspection can have ironic effects. For example, systematically analyzing positive life events can reduce overall life satisfaction (Lyubomirsky, Sousa, \& Dickerhoof, 2006). Direct attempts to articulate the reasons why an intimate relationship is valued can reduce satisfaction with the relationship itself (Wilson \& Kraft, 1993). Thus, direct attempts to generate meaning may also fall short of the stated intent. Just as Koo et al. (2008) found that mentally subtracting events for which individuals are grateful actually increases reported gratitude relative to simply contemplating gratitude, we predicted that counterfactual thinking would imbue turning points with greater significance than directly reflecting on their meaning.

Finally, we coded the content of turning-point descriptions to determine whether the link between counterfactual reflection and meaning is limited to experiences that were positive to begin with, as positive affect is associated with the experience of meaning in life (King, Hicks, Krull, \& Del Gaiso, 2006). Past research on the effect of mutating events from the past has dealt with positive contexts (e.g., subtracting positive events; Koo et al., 2008). Likewise, the educational choices and close relationships examined in our first and second experiments were likely to be deemed positive experiences in participants' lives. Given the inherent positivity of these topics, it is not surprising that participants' counterfactual

\footnotetext{
${ }^{1}$ To assess whether the degree of elaboration was equivalent across the two conditions, we measured the length of the essay (the percentage of the page that was written on) and determined that engagement in factual ( $M=$ $0.73, S D=0.28)$ versus counterfactual $(M=0.63, S D=0.26)$ reflection did not significantly affect essay length, $t(40)=1.33, p=.19$.
} 
thoughts in Study 2 were predominantly downward in direction. It remains unclear, however, whether counterfactual reflection produces meaning for more painful experiences (e.g., the loss of relationships or even life) that may lead to the spontaneous generation of upward counterfactuals and their ensuing negative emotional reactions such as regret (Davis, Lehman, Wortman, Silver, \& Thompson, 1995; Medvec, Madey, \& Gilovich, 1995). Вy coding turning-point descriptions, we could assess whether the relationship between counterfactuals and meaning holds across a range of affectively valenced events.

Because life stories filled with redemptive sequences that transform negative into positive are considered a hallmark of psychological well-being (McAdams, 2006; Tomkins, 1987), we expected the spontaneous generation of downward counterfactuals, or the articulation of how life would be worse if the turning point had never happened, would produce meaning-filled life narratives across a range of affectively valenced turning-point experiences. Similarly, breast cancer patients are adept at constructing downward alternatives in the face of their health crises, finding and comparing themselves with those with even worse states. The woman who is able to avoid a mastectomy imagines the woman with a single mastectomy who envisions the woman with a double mastectomy who thinks of the woman who did not survive (Wood, Taylor, \& Lichtman, 1985). Even in objectively negative situations, humans are strikingly adept at identifying ways in which they could be worse off, and this selectivity should enhance meaning.

To test these hypotheses, we manipulated counterfactual reflection using a procedure similar to that of Experiment 3. As in the previous experiment, all participants first briefly identified a turning point. We then made one procedural modification to facilitate content coding. Following the reflection instructions, rather than writing a free-form essay about their turning point (as in Experiment 3), participants wrote discrete reflection statements about the turning point. We then coded the separate statements for their affective valence. We included three measures assessing reactions to the turning point: meaning, fate perceptions, and whether the individual was better off as a result of the turning point (recognition of a benefit).

\section{Method}

Participants and design. Ninety-four participants (29 men and 65 women) completed the questionnaire. The mean age of the sample was 20.6 years $(S D=3.6)$. Of the 94 participants, one (1\%; female) identified herself as Black or African American, 57 (61\%; 22 male, 35 female) identified themselves as Asian or Asian American, three (3\%; one male, two women) identified themselves as Native Hawaiian or Pacific Islander, five (5\%; two male, three female) identified themselves as Hispanic or Latino, 22 (23\%; three male, 19 female) identified themselves as White. Four participants identified themselves as multiracial (4\%; all female), and two participants $(2 \%$, one female, one male) did not indicate their ethnicity. Participants were randomly assigned to one of three reflection conditions (counterfactual vs. factual vs. meaning).

Procedure. We followed the procedure from Experiment 3. However, rather than writing a free-form essay about their turning point, participants wrote a series of discrete statements about the turning point. We also added a meaning condition, in which participants were instructed to "Describe the significance of the turning point incident in detail. Please write about exactly how this incident made you who you are today, led you to a deeper understanding of yourself, shaped your current beliefs, emotional wellbeing, and values, or any other personally meaningful aspects of the incident that you can recall."

Next, we assessed turning-point meaning with two items ( $\alpha=$ .68): "It made me who I am today" and "It gave meaning to my life." We also assessed valence of the turning point's outcome. For negativity, we included two items $(\alpha=.75)$ : "As a result, I am sadder" and "Overall, the outcome was negative." For positivity ("benefit-finding"), we included two items $(\alpha=.93)$ : "As a result, I am happier" and "Overall, the outcome was positive." Finally, we assessed fate perceptions with the identical single-item measure from Study 3. All response scales ranged from 1 (not at all) to 9 (extremely).

Coding of the premanipulation turning point descriptions. In addition to self-assessed valence of the turning point, we had independent coders judge the valence of the events. Two coders who were blind to experimental condition evaluated the onesentence turning-point descriptions that were written prior to receiving the reflection instructions (premanipulation). Coders categorized each turning point as either clearly negative (i.e., "My mother died of breast cancer"), clearly positive (i.e., "The day I met my current husband"), or neutral (i.e., "I moved to San Francisco"). Statements suggesting ambivalence (i.e., "I didn't get accepted into Penn and so decided to go to Berkeley") were also coded as neutral. The inter-rater reliability of the classifications was high $(\kappa=.88, p<.001)$.

Coding of the postmanipulation turning point reflections. We also coded the postmanipulation statements of the turningpoint analysis by having two independent judges code whether each statement was factual (described the event itself or some outcome of it) or counterfactual (described an alternative possible reality, identified by an implicit "if-then" subjunctive conditional). ${ }^{2}$ Then for each factual statement, coders rated the valence of each thought (positive, $\kappa=.97, p<.001$; negative, $\kappa=.91, p<$ .001 ; and neutral, $\kappa=.97, p<.001$ ). For each counterfactual statement, the coders determined whether it referred to a downward counterfactual world ("I wouldn't be so adaptable to people and situations"), an upward counterfactual world ("I would probably have stronger relationships with high school friends"), or a neutral counterfactual world ("I might be back at home in Southern California going to UCLA"). As reliability was high for each coding (positive, $\kappa=.87, p<.001$; negative, $\kappa=.88, p<.001$; neutral, $\kappa=.87, p<.001)$, we averaged the ratings for our analyses.

\section{Results}

Turning-point meaning. As shown in Figure 1, a one-way analysis of variance (ANOVA) revealed a significant effect of type of reflection on meaning, $F(2,91)=5.17, p=.007$. Counterfac-

\footnotetext{
${ }^{2}$ Coders also measured the degree of elaboration by counting the number of thoughts participants listed about the turning point. An ANOVA found that the number of thoughts listed across conditions was not statistically significant ( $p=.20$, overall $M=7.51, S D=2.23$ ), suggesting that the degree of elaboration does not account for our findings.
} 

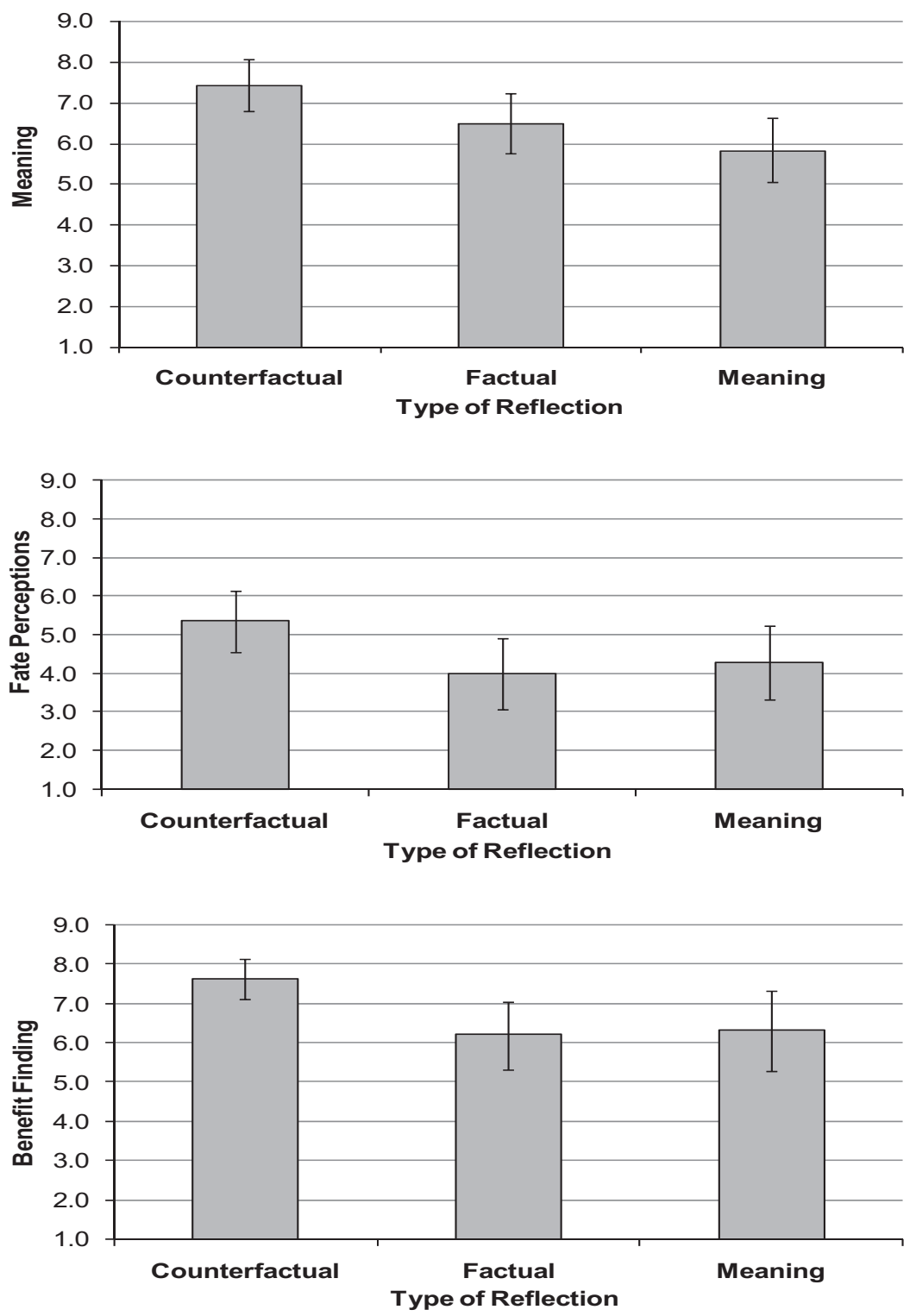

Figure 1. Mean ratings of fate perceptions for each type of reflection $(1=$ not at all determined by fate $9=$ extremely determined by fate). Bars indicate $95 \%$ confidence intervals for the means.

tual reflection $(M=7.42, S D=1.80)$ led to more meaning than either factual reflection $(M=6.48, S D=2.03), t(91)=1.92, p=$ $.06, d=0.49$, or directly reflecting on the turning point's meaning $(M=5.83, S D=2.08), t(91)=3.19, p=.002, d=0.82$. The meaning and factual conditions did not differ, $t(91)=1.30, p=$ $.20, d=0.32$. Replicating Experiments 1 and 2, counterfactual reflection served as a linchpin in the quest for meaning.

Fate perceptions. Replicating our third experiment, a oneway ANOVA revealed that fate perceptions were influenced by type of reflection, $F(2,91)=2.87, p=.06$. Counterfactually undoing a turning point $(M=5.36, S D=2.25)$ increased perceptions of fate relative to the factual condition $(M=4.00, S D=$ $2.51), t(91)=-2.27, p=.03, d=0.57$, and marginally compared with the meaning condition $(M=4.28, S D=2.51), t(91)=-1.77$, $p=.08, d=0.45$, whereas the latter two conditions did not differ $t(91)=-0.44, p=.68, d=0.11$.

Positive outcome valence ("benefit-finding"). A one-way ANOVA revealed that type of reflection predicted benefit-finding, $F(2,91)=4.14, p=.02$. Counterfactual reflection $(M=7.64$, $S D=1.43$ ) produced more positive assessments of the turning point's consequences than did factual reflection $(M=6.20, S D=$ 2.43), $t(91)=-2.59, p=.01, d=0.73$, and explicit reflection on meaning $(M=6.31, S D=2.69), t(91)=-2.34, p=.02, d=0.63$, with no significant difference between the factual and meaning conditions, $t(91)=-0.19, p=.85, d=0.04$.

Negative outcome valence. A one-way ANOVA revealed that the effect of experimental condition on negative assessments was not statistically significant $(p>.28)$. 
Mediation analyses. We examined whether fate perceptions and benefit-finding (which were uncorrelated; $r=.06, p=.58$ ) mediated the relation between counterfactual reflection and meaning (see Figure 2). Because the meaning and factual conditions showed no significant differences, we combined them for these analyses. To test for mediation, we regressed meaning on type of reflection, fate perceptions, and benefit-finding perceptions. Both the effects of fate perceptions $(\beta=.33, B=0.27, S E=0.08, p=$ $.001)$ and benefit-finding $(\beta=.35, B=0.31, S E=0.08, p=$ $.001)$ remained significant, whereas type of reflection dropped to nonsignificance $(\beta=.11, B=0.24, S E=0.20, p=.23$ ). Two separate Sobel tests established mediation for both fate perceptions $(z=1.93, p=.05)$ and benefit-finding $(z=2.23, p=.03)$. Our results suggest that counterfactual reflection produced meaning by influencing the degree to which pivotal life events were judged to be fated and viewed as catalysts for positive growth. ${ }^{3}$

\section{Analysis of turning-point valence.}

Premanipulation turning point description. Participants' turning points represented a broad range of affective experiences, which allowed us to determine whether valence moderated the power of counterfactual reflection to create meaning. As expected, the sample included a full spectrum of turning point valences (39.4\% negative, $38.3 \%$ positive, $22.3 \%$ neutral). We reran all of the preceding analyses while including valence of the turning point as a factor. Valence did not moderate any of the reported findings (all $p \mathrm{~s} \geq .17),{ }^{4}$ indicating that counterfactual reflection enhanced meaning across a wide range of life experiences, positive, negative, or neutral.

Postmanipulation turning point reflection. We analyzed whether the valence of the factual and counterfactual statements differed by condition. Looking at each type of factual statement (positive, negative, and neutral) separately with one-way ANOVAs revealed that all omnibus effects were statistically significant-positive, $F(2,91)=45.92, p<.001$; negative, $F(2$, $91)=18.45, p<.001$; and neutral, $F(2,91)=52.62, p<.001$. As can be seen in Table 1 , both the meaning and the factual conditions produced more factual statements of all types of valence compared with the counterfactual condition, with the factual condition producing more negative and neutral thoughts but fewer positive thoughts than the meaning condition. When we analyzed each type of counterfactual statement, each omnibus effect was
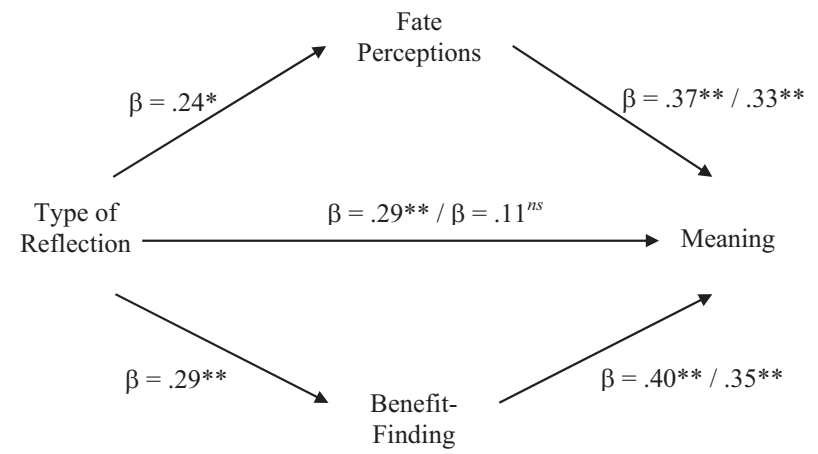

Figure 2. Fate perceptions and benefit-finding as mediators of the effect of reflection type on meaningfulness of turning points. Coefficients to the left of backslashes correspond to the direct effect. Asterisks indicate parameter estimates significantly different from zero. ${ }^{*} p<.05$. ${ }^{* *} p<.01$. statistically significant-positive, $F(2,91)=20.72, p<.001$; negative, $F(2,91)=123.48, p<.001$; and neutral, $F(2,91)=$ 37.91, $p<.001$. Although the factual and meaning conditions produced almost no counterfactual thoughts, participants in the counterfactual condition expressed a particularly large number of downward counterfactual thoughts. The majority of statements generated by participants engaged in counterfactual reflection highlighted worse possible worlds.

We also examined whether premanipulation turning-point valence interacted with type of reflection to affect postmanipulation turning-point statement valence. To do so, we conducted separate two-way ANOVAs for each type of statement. None of the interactions emerged as statistically significant. Most importantly, premanipulation turning-point valence did not interact with reflection type in predicting the number of downward counterfactual thoughts, $F(4,85)=.85, p=.50$. Thus, regardless of whether the participant recalled a positive, neutral, or negative event, counterfactual reflection increased the expression of downward counterfactual thoughts.

Next we examined how the type of turning-point statements related to our key dependent variables (meaning, fate, and benefitfinding). As shown in Table 2, the generation of downward counterfactuals, or imagined worlds that are worse than reality, was positively associated with meaning, fate perceptions, and benefitfinding. Given the strong relationship between downward counterfactual generation and our dependent variables, we conducted separate mediation analyses, combining the factual and meaning conditions as in our earlier mediation analysis. Fate perception was the sole variable for which downward counterfactuals served as a mediator. Specifically, we regressed fate perceptions on type of reflection and downward counterfactual generation. The effect of downward counterfactuals remained significant $(\beta=.47, B=$ $0.45, S E=0.18, p=.02)$, whereas type of reflection dropped to nonsignificance $(\beta=.16, B=0.84, S E=.98, p=.39)$. A Sobel test confirmed mediation $(z=3.30, p<.001)$. The construction of a downward counterfactual universe, in which a pivotal turning point's nonoccurrence leads to a worse possible world, led to a sense that the turning point was fated.

\section{Discussion}

Experiment 4 explored the underlying processes through which counterfactual thinking creates meaning. First, we replicated the

\footnotetext{
${ }^{3}$ Because fate perceptions and benefit-finding are uncorrelated, the current simultaneous regression model is the only statistically significant model involving all three variables. However, examining meaning with just fate perceptions or benefit-finding suggests bidirectional relationships That is, meaning mediates the link between reflection condition and fate perceptions (Sobel's $z=-2.34, p=.02$ ); meaning also mediates the link between reflection condition and benefit-finding (Sobel's $z=-2.40, p=$ .02). Meaning appears to be interwoven in such a way with fate and benefits that they are difficult to disentangle in the construction of life stories. Because meaning is the most theoretically understood and important outcome variable, we present in the text the model in which fate and benefit-finding serve as simultaneous predictors of meaning.

${ }^{4}$ The interaction between event valence and type of reflection follows for each dependent variable: meaning, $F(4,85)=1.36, p=.26$; fate perceptions, $F(4,85)=.74, p=.57$; benefit-finding, $F(4,85)=$ $1.60, p=.18$.
} 
Table 1

Experiment 4: Mean and Standard Deviation of Type of Turning-Point Statement by Type of Reflection

\begin{tabular}{|c|c|c|c|c|c|c|}
\hline \multirow{2}{*}{$\begin{array}{c}\text { Type of turning-point } \\
\text { statement }\end{array}$} & \multicolumn{2}{|c|}{$\begin{array}{l}\text { Counterfactual } \\
\text { reflection }\end{array}$} & \multicolumn{2}{|c|}{ Factual reflection } & \multicolumn{2}{|c|}{ Meaning reflection } \\
\hline & $M$ & $S D$ & $M$ & $S D$ & $M$ & $S D$ \\
\hline Negative factual & $0.48_{\mathrm{a}}$ & 0.95 & $3.30_{b}$ & 2.12 & $2.12_{\mathrm{c}}$ & 2.33 \\
\hline Positive factual & $0.20_{\mathrm{a}}$ & 0.47 & $1.88_{\mathrm{b}}$ & 1.48 & $3.83_{\mathrm{c}}$ & 2.13 \\
\hline Neutral factual & $0.09 \mathrm{a}$ & 0.32 & $2.66_{b}$ & 1.38 & $0.78_{\mathrm{a}}$ & 1.13 \\
\hline Downward counterfactual & $4.70_{\mathrm{a}}$ & 2.28 & $0.02_{\mathrm{b}}$ & 0.09 & $0.07_{\mathrm{b}}$ & 0.37 \\
\hline Upward counterfactual & $1.18_{\mathrm{a}}$ & 1.32 & $0.00_{\mathrm{b}}$ & 0.00 & $0.099_{b}$ & 0.46 \\
\hline Neutral counterfactual & $1.08_{\mathrm{a}}^{\mathrm{a}}$ & 0.95 & $0.00_{\mathrm{b}}$ & 0.00 & $0.12_{\mathrm{b}}$ & 0.09 \\
\hline
\end{tabular}

Note. Means in the same row that do not share subscripts differ at $p<.05$ in the Tukey honestly significant difference comparison.

previous finding that counterfactual reflection heightens perceptions of fate, which fully mediated the relationship between counterfactual reflection and meaning. We also observed an additional pathway by which counterfactuals are connected to finding meaning in events: the discovery of benefits. By contrasting reality with what might have been, participants gained clarity about the positive consequences of their turning point. Fate perceptions and benefit-finding independently connected counterfactuals to meaning. The fact that the fate-based and benefit-finding-based mediators were uncorrelated with each other highlights the multiple paths connecting counterfactual reflection to meaning.

Another goal of Experiment 4 was to contrast counterfactual thinking with more straightforward attempts to generate meaning. Because introspective access to internal states is often limited (Nisbett \& Wilson, 1977), we expected the cognitive contrast between reality and a hypothetical alternative to be particularly useful for generating meaning. Remarkably, mentally undoing the turning point led participants to derive more meaning from the turning point than did directly pondering the meaning of the event. Despite similar levels of abstract reflection and cognitive elaboration required across tasks, it was only in the counterfactual condition that increased fate perceptions, recognition of more positive consequences, and a stronger sense of meaning emerged. The contrast between reality and what might have been seems to crystallize an event's significance in a way that direct attempts to generate its meaning cannot.

By coding the valence of participants' self-selected turning points, we were able to assess whether the meaning-enhancing effect of counterfactual thought was limited to affectively positive events. Past research has made clear that the regret emerging from elaborating on lost possible selves actually contributes to a sense of complexity and happiness, two defining aspects of maturity (King \& Hicks, 2007). Indeed, the search for positive outcomes is a key ingredient of maturity (McAdams, 2006). The absence of an interaction between turning-point valence and counterfactual reflection suggests that the observed effects are most likely not driven by affective contrast alone (cf. Roese, 1997). Across an impressively wide spectrum of events, mentally undoing a turning point made that event more fated, more positive, and ultimately a more meaningful part of one's life.

We also coded the reflection statements that participants generated about their turning points. Doing so revealed, first, that counterfactual reflection predominantly involved the spontaneous generation of downward counterfactuals, or considerations of worse possible worlds if the turning point had not occurred. Second, the generation of downward counterfactuals was predictive of each of our key dependent variables, including meaning, fate perceptions, and benefit-finding. The generation of downward

Table 2

Experiment 4: Intercorrelations Between Turning Point Statements and Dependent Variables

\begin{tabular}{|c|c|c|c|c|c|c|c|}
\hline Dependent measure & $M$ & $S D$ & $N$ & Meaning & Fate & Benefit-finding & $\begin{array}{l}\text { Negative outcome } \\
\text { valence }\end{array}$ \\
\hline Meaning & 6.61 & 2.06 & 94 & - & & & \\
\hline Fate & 4.56 & 2.47 & 94 & $.37^{* * *}$ & - & & \\
\hline Benefit-finding & 6.74 & 2.30 & 94 & $.40^{\text {*** }}$ & .06 & - & \\
\hline Negative outcome valence & 3.48 & 2.13 & 94 & $-.30^{\text {** }}$ & -.02 & $-.81^{* *}$ & - \\
\hline TP negative fact & 1.87 & 2.45 & 94 & $-.21^{*}$ & -.02 & $-.62^{* *}$ & $.48^{* *}$ \\
\hline TP positive fact & 1.73 & 2.13 & 94 & -.16 & $-.22^{*}$ & .07 & -.11 \\
\hline TP neutral fact & 1.14 & 1.85 & 94 & -.04 & -.17 & -.02 & -.05 \\
\hline TP downward CF & 1.84 & 2.78 & 94 & $.34^{* *}$ & $.33^{* *}$ & $.28^{* *}$ & -.19 \\
\hline TP upward CF & 0.50 & 1.25 & 94 & $.21^{*}$ & .17 & .18 & -.04 \\
\hline TP neutral CF & 0.43 & 0.85 & 94 & .12 & .10 & $.20^{*}$ & -.04 \\
\hline
\end{tabular}

Note. $\quad \mathrm{TP}=$ turning point $; \mathrm{CF}=$ counterfactual

${ }^{*} p<.05$. **** $p<.01$. 
counterfactuals fully mediated the relationship between how turning points were reflected upon and the sense that they were fated. Because the construction of a narrative identity is a subjective experience akin to storytelling (McAdams, Josselson, \& Lieblich, 2001), individuals are given wide latitude to choose the story they tell. The current research suggests that one's destiny-manifested as a result of pivotal life transitions-is developed in part by selectively focusing on the ways in which life would have been worse had the event never occurred. By considering how the absence of a turning point (regardless of its seeming valence) would diminish one's life in various ways, the role of fate emerged.

\section{General Discussion}

Individuals create meaning in their lives, which affords great benefits to physical and psychological well-being (Frankl, 1963; Janoff-Bulman, 1992; Updegraff et al., 2008). Across four experiments, we have established a strong link between counterfactual thinking and the meaning derived from life events and relationships. Considering how pivotal events and relationships might have unfolded differently solidifies their meaning and significance in one's life. By considering what might have been, individuals construct life stories that are more meaningful.

This connection between counterfactual thought and meaning is driven by at least two psychological processes. Consistent with past research identifying the psychological benefits of constructing redemptive life stories (McAdams, 2006), individuals in the current set of experiments derived more meaning from critical life experiences when they perceived them to be the products of destiny. Rather than rendering reality a fluke, counterfactually undoing metaphorical forks in the path of life has an ironic effect of bolstering the sense that the actual path taken was fated. "What might have been" musings anchor reality with a sense of destiny. Like the hindsight certainty triggered by counterfactual reflection (Roese \& Olson, 1996), highlighting the sheer improbability of an event's occurrence through pondering its nonoccurrence rendered it as meant to be. These results suggest that perceptions of fate are a strong precursor to finding meaning; believing that an event was meant to be elevates its significance. ${ }^{5}$

Counterfactual reflection also enhances meaning by highlighting the benefits and growth opportunities of pivotal events, seeing them as catalysts for identifiable positive consequences. Finding benefits in the face of adversity is a well-established coping mechanism (Affleck \& Tennen, 1996; Taylor, Lichtman, \& Wood, 1984) to which it is possible to attach starkly different value judgments. From the most critical standpoint, one could view the observed patterns of reasoning as absurdly Panglossian (it is wonderful to live in the "best of all possible worlds" - and all we can see around us are worse possible worlds) or at least as a stubbornly defensive refusal to accept the possibility that, within the spectrum of once possible worlds, the world one inhabits is, if not the worst of all possible worlds, at best manifestly suboptimal. From a more charitable perspective, one could argue that the optimist's ability to see the benefits of even negative events is an essential component of psychological well-being for creatures whose existence is as precarious as ours (Nes \& Segerstrom, 2006; Taylor \& Brown, 1988).
The current research contributes to the benefit-finding literature in two ways. First, we identify a tool by which benefits may more easily crystallize, namely, the mental simulation of what might have been. It is remarkable that counterfactual reflection may be a more productive means of generating meaning than explicitly pondering the significance of pivotal life events. Second, beyond McAdams's (2006) work on redemption sequences that emphasize a negative-to-positive pattern, the current research shows that meaning can be extracted from positive or affectively neutral starting points via their juxtaposition against worse possible counterfactual worlds. By engendering both a sense of destiny and optimism, the spontaneous generation of downward counterfactual comparisons may help individuals imbue particular events with special meaning.

As fate perceptions and benefit-finding were uncorrelated in our final experiment, it raises the question of what drives differences between these two pathways toward meaning. The fact that these two variables are temporally distinct-in that fate is a perceived antecedent of an event, whereas benefits represent interpretations of an event's consequences-may explain their orthogonality. Although the coping-with-adversity literature has covered considerable ground in identifying predictors of benefit-finding, little is known about what determines whether fate is employed as an explanatory device for an event's occurrence. To the degree that fate perceptions represent nonmaterial beliefs invoked when material explanations for unexpected major events fall short (Pepitone \& Saffiotti, 1997), religiosity (Young \& Morris, 2004) may be a relevant moderator. If fate perceptions are driven by a desire to create structure or control in one's life, then individual differences in locus of control (Rotter, 1966) and need for closure (Kruglanski $\&$ Webster, 1996) may predict the use of fate as an explanatory device.

Throughout this article we have emphasized the constructive process by which counterfactual reflection and meaning are related. Building on earlier work elucidating how counterfactual thinking fortifies connections between knowledge and concepts (Kray et al., 2006; Wells \& Gavanski, 1989), we have argued that counterfactual thinking also helps in the construction of meaningful life stories. Alternatively, it is worth considering to what extent counterfactual thinking provokes existential angst and thereby serves as a catalyst for defensive meaning-making (Becker, 1971; Pyszczynski, Greenberg, Solomon, Arndt, \& Schimel, 2004; Solomon et al., 1991). A growing body of literature documents the myriad ways in which compensatory or defensive meaningmaking processes are activated when one's sense of control or order is threatened (Heine, Proulx, \& Vohs, 2006; Whitson \& Galinsky, 2008). Even close-call counterfactuals can trigger belief-

\footnotetext{
${ }^{5}$ Whereas the current studies have consistently found that contemplating alternative counterfactual paths in personal life histories increases the sense that the outcomes were fated or "had to be," Tetlock and Lebow (2001) found that contemplating counterfactuals appeared to have the opposite effects on professional historians retrospectively judging the exact dates by which major geopolitical events became inevitable. The different findings may well reflect the greater professional detachment of the experts toward distant events of low personal relevance. Our argument here applies to how ordinary people make sense of their own life histories, and not necessarily to how professionals make sense of complex causal sequences far removed from their everyday lives.
} 
system defense among political experts committed to the theoretical view that certain things had to happen (Tetlock, 1998). However, in the construction of personal life narratives, individuals have wide latitude to choose which events are pivotal (and how to interpret them), making veridicality an elusive notion. Definitively ruling out the possibility that efforts to construct personal meaning simply reflect a defensive process may well ultimately prove impossible. In the current research, we contend that, because event valence did not moderate the link between counterfactual reflection and meaning, our findings are more consistent with a constructive process than with a defensive one. Presumably, threat would be particularly acute following the counterfactual deletion of cherished events and relationships from one's life. Nonetheless, future research should continue to try to tease apart these possibilities.

Another unresolved question centers on the boundary conditions of the counterfactual and meaning effect we have uncovered. Much earlier research has suggested dysfunctional consequences of counterfactual thinking. For the most part, it has been upward (as opposed to downward) counterfactual thoughts and their emotional offspring of regret that have been connected to biased judgments (e.g., Kruger, Wirtz, \& Miller, 2005; Sherman \& McConnell, 1995), coping difficulties (Davis et al., 1995), and emotional disorders such as depression and anxiety (Lecci, Okun, \& Karoly, 1994; Leithy, Brown, \& Robbins, 2006; Monroe, Skowronski, MacDonald, \& Wood, 2005). However, in the present research, we found that it is mainly downward, not upward, counterfactuals that were associated with increased perception of meaning. Thus, it may be that the upward versus downward direction of counterfactual comparison moderates whether dysfunctional or functional consequences emerge.

Another interesting question is under what circumstances counterfactual reflection fails to produce meaning and instead simply triggers repetitive thought - that is, one that repeatedly comes to mind in essentially the same form, day after day (e.g., NolenHoeksema, Wisco, \& Lyubomirsky, 2008; Segerstrom, Stanton, Alden, \& Shortridge, 2003; Watkins, 2008). Roese et al. (2009) found that the association between regret and depression was particularly strong among repetitive thinkers. Although regrets may yield lessons for improvement, such lessons may be overwhelmed by the negative emotional tone that is amplified as individuals ruminate on those regrets. By contrast, regrets that are quick to dissipate are associated with more effective problemsolving and sturdier emotional health. There might be a general pattern, therefore, in which counterfactual thinking that becomes repetitive might be robbed of its psychological benefits, including the making of meaning, and simply leaves people "spinning their wheels" over the past. ${ }^{6}$

A potential moderator of whether counterfactual thinking produces rumination versus constructive meaning-making is temporal distance. Events from the near past may be too emotionally raw to unpack counterfactually (Wilson \& Gilbert, 2008), whereas reflection on events from the more distant past may create meaning because enough time has passed to allow positive downstream consequences to emerge (Schwarzer, Luszczynska, Boehmer, Tauber, \& Knoll, 2006). Increasing the perceived temporal distance from an event may allow a more abstract construal of what happened to emerge that begins to address the meaning question (Brewer, 1986). The passage of time tends to transform a purely reproductive retelling of what happened to a more reconstructive account (Thompson, Skowronski, Larsen, \& Betz, 1996) that "functions primarily to maintain personal coherence rather than provide an objective report of what has transpired in one's life" (McAdams, 2006, p. 314).

In considering the implications of the current research, it is important to note that we examined how individuals made sense of specific choices, events, and relationships in their lives and how meaningful those events were in their lives, rather than assessing overall meaning in life. One unresolved question is whether mentally undoing multiple individual events can heighten life's meaning overall. Just as the benefits of daily experiences with positive emotions accrue over time (Fredrickson, 1998), it is possible that getting in the habit of considering alternative counterfactual worlds may heighten our appreciation of the world we happen to inhabit. Of course, future research is important for establishing the duration and scope of the effects of counterfactual reflection.

\section{Conclusion}

As the need to find meaning in life is a pervasive part of human experience, the implications of the current research are farreaching. How people reflect on their past offers profound insight into the human condition-who we are and why we are here. The current research makes clear that counterfactual thinking, the pondering of what might have been, brings us - at least subjectivelycloser to answering these timeless questions. Far from rendering reality a low-probability product of random forces, counterfactual reflection extracts meaning from choices, relationships, and pivotal experiences. From reflections in a personal diary to analyses of world history, counterfactual thinking can alter our understanding of life. Mentally veering off the path of reality, only briefly and imaginatively, forges key connections between what might have been and what was meant to be, thereby injecting our experiences and relationships with deeper meaning and significance.

\footnotetext{
${ }^{6} \mathrm{We}$ also see it as an open empirical question whether there is an extreme-negativity boundary condition on the reported effects, in which people see their current reality as so grim that counterfactual reflection yields only better possible worlds and amplifies despair.
}

\section{References}

Affleck, G., \& Tennen, H. (1996). Construing benefits from adversity: Adaptational significance and dispositional underpinnings. Journal of Personality, 64, 899-922.

Baumeister, R. (1991). Meanings of life. New York, NY: Guilford Press. Becker, E. (1971). The birth and death of meaning. New York, NY: Free Press.

Brewer, W. F. (1986). What is autobiographical memory? In D. Rubin (Ed.), Autobiographical memory (pp. 25-49). New York, NY: Cambridge University Press.

Bruner, J. S. (1990). Acts of meaning. Cambridge, MA: Harvard University Press.

Bruner, J. S. (1991). The narrative construction of reality. Critical Inquiry, $18,1-21$.

Burrus, J., \& Roese, N. J. (2006). Long ago it was meant to be: The interplay between time, construal, and fate beliefs. Personality and Social Psychology Bulletin, 32, 1050-1058.

Camille, N., Coricelli, G., Sallet, J., Pradet-Diehl, P., Duhamel, J. M., \& 
Sirigu, J. (2004, May 21). The involvement of the orbitofrontal cortex in the experience of regret. Science, 304, 1167-1170.

Dai, X., Wertenbroch, K., \& Brendl, C. M. (2008). The value heuristic in judgments of relative frequency. Psychological Science, 19, 18-19.

Davis, C. G., Lehman, D. R., Wortman, C. B., Silver, R. C., \& Thompson, S. C. (1995). The undoing of traumatic life events. Personality and Social Psychology Bulletin, 21, 109-124.

Davis, C. G., Nolen-Hoeksema, S., \& Larson, J. (1998). Making sense of loss and benefiting from the experience: Two construals of meaning. Journal of Personality and Social Psychology, 75, 561-574.

Einhorn, H. J., \& Hogarth, R. M. (1986). Judging probable cause. Psychological Bulletin, 99, 3-19.

Epstude, K., \& Roese, N. J. (2008). The functional theory of counterfactual thinking. Personality and Social Psychology Review, 12, 168-192.

Frankl, V. E. (1963). Man's search for meaning: An introduction to logotherapy. New York, NY: Washington Square Press.

Fredrickson, B. L. (1998). What good are positive emotions? Review of General Psychology, 2, 300-319.

Galinsky, A. D., Liljenquist, K. A., Kray, L. J., \& Roese, N. R. (2005). Finding meaning from mutability: Making sense and deriving meaning from counterfactual thinking. In D. R. Mandel, D. J. Hilton, \& P. Catellani (Eds.), The psychology of counterfactual thinking (pp. 110125). London, England: Routledge.

Giddens, A. (1991). Modernity and self identity. Stanford, CA: Stanford University Press.

Heine, S. J., Proulx, T., \& Vohs, K. D. (2006). The meaning maintenance model: On the coherence of social motivations. Personality and Social Psychological Review, 10, 88-111.

Janoff-Bulman, R. (1992). Shattered assumptions: Towards a new psychology of trauma. New York, NY: Free Press.

Janoff-Bulman, R., \& Frantz, C. M. (1997). The impact of trauma on meaning: From meaningless world to meaningful life. In M. J. Power \& C. R. Brewin (Eds.), The transformation of meaning in psychological therapies: Integrating theory and practice (pp. 91-106). Chichester, England: Wiley.

Kahneman, D., \& Miller, D. T. (1986). Norm theory: Comparing reality to its alternatives. Psychological Review, 93, 136-153.

King, L. A., \& Hicks, J. A. (2007). Whatever happened to "what might have been"? Regrets, happiness, and maturity. American Psychologist, 62, 625-636.

King, L. A., Hicks, J. A., \& Abdelkhalik, J. (in press). Death, life, scarcity, and value: An alternative perspective on the meaning of death. Psychological Science.

King, L. A., Hicks, J. A., Krull, J. L., \& Del Gaiso, A. K. (2006). Positive affect and the experience of meaning in life. Journal of Personality and Social Psychology, 90, 179-196.

King, L. A., \& Napa, C. K. (1998). What makes a life good? Journal of Personality and Social Psychology, 75, 156-165.

Koo, M., Algoe, S. B., Wilson, T. D., \& Gilbert, D. T. (2008). It's a wonderful life: Mentally subtracting positive events improves people's affective states, contrary to their affective forecasts. Journal of Personality and Social Psychology, 95, 1217-1224.

Kray, L. J., Galinsky, A. D., \& Markman, K. D. (2009). Counterfactual structure and learning from experience in negotiations. Journal of Experimental Social Psychology, 45, 979-982.

Kray, L. J., Galinsky, A. D., \& Wong, E. (2006). Thinking inside the box: The relational processing style elicited by counterfactual mind-sets. Journal of Personality and Social Psychology, 91, 33-48.

Kruger, J., Wirtz, D., \& Miller, D. (2005). Counterfactual thinking and the first instinct fallacy. Journal of Personality and Social Psychology, 88, 725-735.

Kruglanski, A. W., \& Webster, D. M. (1996). Motivated closing of the mind: "Seizing" and "freezing." Psychological Review, 103, 263-283.

Kurdek, L. A. (1999). The nature and predictors of the trajectory of change in marital quality for husbands and wives over the first 10 years of marriage. Developmental Psychology, 35, 1283-1296.

Landman, J., \& Petty, R. (2000). "It could have been you": How states exploit counterfactual thought to market lotteries. Psychology and Marketing, 17, 299-321.

Lecci, L., Okun, M. A., \& Karoly, P. (1994). Life regrets and current goals as predictors of psychological adjustment. Journal of Personality and Social Psychology, 66, 731-741.

Lehman, D. R., Davis, C. G., DeLongis, A., Wortman, C., Bluck, S., Mandel, D. R., \& Ellard, J. H. (1993). Positive and negative life changes following bereavement and their relations to adjustment. Journal of Social and Clinical Psychology, 12, 90-112.

Leithy, S. E., Brown, G. P., \& Robbins, I. (2006). Counterfactual thinking and posttraumatic stress reactions. Journal of Abnormal Psychology, 115, 629-635.

Leontiev, D. A. (2005). Three facets of meaning. Journal of Russian and East European Psychology, 43, 45-72.

Lyubomirsky, S., Sousa, L., \& Dickerhoof, R. (2006). The costs and benefits of writing, talking, and thinking about life's triumphs and defeats. Journal of Personality and Social Psychology, 90, 692-708.

Mandel, D. R. (2003). Judgment dissociation theory: An analysis of differences in causal, counterfactual and covariational reasoning. Journal of Experimental Psychology: General, 132, 419-434.

Mandel, D. R., \& Lehman, D. R. (1996). Counterfactual thinking and ascriptions of cause and preventability. Journal of Personality and Social Psychology, 71, 450-463.

McAdams, D. P. (2001). The psychology of life stories. Review of General Psychology, 5, 100-122.

McAdams, D. P. (2006). The redemptive self: Stories Americans live by. New York, NY: Oxford University Press.

McAdams, D. P., Josselson, R., \& Lieblich, A. (2001). Turns in the road: Narrative studies of lives in transition. Washington, DC: American Psychological Association.

McAdams, D. P., Reynolds, J., Lewis, M., Patten, A. H., \& Bowman, P. J. (2001). When bad things turn good and good things turn bad: Sequences of redemption and contamination in life narrative and their relation to psychosocial adaptation in midlife adults and in students. Personality and Social Psychology Bulletin, 27, 474-485.

McGregor, I., \& Little, B. R. (1998). Personal projects, happiness, and meaning: On doing well and being yourself. Journal of Personality and Social Psychology, 74, 494-512.

McNamara, P., Durso, R., Brown, A., \& Lynch, A. (2003). Counterfactual cognitive deficit in patients with Parkinson's disease. Journal of Neurology, Neurosurgery, and Psychiatry, 74, 1065-1070.

Medvec, V. H., Madey, S. F., \& Gilovich, T. (1995). When less is more: Counterfactual thinking and satisfaction among Olympic athletes. Journal of Personality and Social Psychology, 69, 603-610.

Miles, M. S., \& Crandall, E. K. B. (1983). The search for meaning and its potential for affecting growth in bereaved parents, Health Values: Achieving High Level Wellness, 7, 19-23.

Miller, D. R., \& Taylor, B. R. (1995). Counterfactual thought, regret, and superstition: How to avoid kicking yourself. In N. J. Roese \& J. M. Olson (Eds.), What might have been: The social psychology of counterfactual thinking (pp. 305-331). Mahwah, NJ: Erlbaum.

Monroe, M. R., Skowronski, J. J., MacDonald, W., \& Wood, S. E. (2005). The mildly depressed experience more post-decisional regret than the non-depressed. Journal of Social and Clinical Psychology, 24, 665-690.

Nes, L. S., \& Segerstrom, S. C. (2006). Dispositional optimism and coping: A meta-analytic review. Personality and Social Psychological Review, $10,235-251$.

Nestler, S., \& von Collani, G. (2008). Hindsight bias and the activation of counterfactual mind-sets. Experimental Psychology, 55, 342-349.

Nisbett, R. E., \& Wilson, T. D. (1977). Telling more than we can know: Verbal reports on mental processes. Psychological Review, 84, 231-259. 
Nolen-Hoeksema, S., Wisco, B. E., \& Lyubomirsky, S. (2008). Rethinking rumination. Perspectives on Psychological Science, 3, 400-424.

Pepitone, A., \& Saffiotti, L. (1997). The selectivity of nonmaterial beliefs in interpreting life events. European Journal of Social Psychology, 27, 23-35.

Pyszczynski, T., Greenberg, J., Solomon, S., Arndt, J., \& Schimel, J. (2004). Why do people need self-esteem? A theoretical and empirical review. Psychological Bulletin, 130, 435-468.

Roese, N. J. (1994). The functional basis of counterfactual thinking. Journal of Personality and Social Psychology, 66, 805-818.

Roese, N. J. (1997). Counterfactual thinking. Psychological Bulletin, 121, 133-148.

Roese, N. J., Epstude, K., Fessel, F., Morrison, M., Smallman, R., Summerville, A., ... Segerstrom, S. (2009). Repetitive regret, depression, and anxiety: Findings from a nationally representative survey. Journal of Social and Clinical Psychology, 28, 671-688.

Roese, N. J., \& Maniar, S. D. (1997). Perceptions of purple: Counterfactual and hindsight judgments at Northwestern Wildcats football games. Personality and Social Psychology Bulletin, 23, 1245-1253.

Roese, N. J., \& Olson, J. M. (1996). Counterfactuals, causal attributions, and the hindsight bias: A conceptual integration. Journal of Experimental Social Psychology, 32, 197-227.

Roese, N. J., Park, S., Smallman, R., \& Gibson, C. (2008). Schizophrenia involves impairment in the activation of intentions by counterfactual thinking. Schizophrenia Research, 103, 343-344.

Rotter, J. (1966). Generalized expectancies for internal versus external control of reinforcement. Psychological Monographs: General \& Applied, 80(1), 1-28.

Saffrey, C., Summerville, A., \& Roese, N. J. (2008). Praise for regret: People value regret above other negative emotions. Motivation and Emotion, 32, 46-54.

Sanna, L. J., \& Turley, K. J. (1996). Antecedents to spontaneous counterfactual thinking: Effects of expectancy violation and outcome valence. Personality and Social Psychology Bulletin, 22, 906-919.

Schwarzer, R., Luszczynska, A., Boehmer, S., Tauber, S., \& Knoll, N. (2006). Changes in finding benefit after cancer surgery and the prediction of well-being one year later. Social Science and Medicine, 63, $1614-1624$

Segerstrom, S. C., Stanton, A. L., Alden, L. E., \& Shortridge, B. E. (2003). A multidimensional structure for repetitive thought: What's on your mind, and how, and how much? Journal of Personality and Social Psychology, 85, 909-921.

Sherman, S. J., \& McConnell, A. R. (1995). Dysfunctional implications of counterfactual thinking: When alternatives to reality fail us. In N. J. Roese \& J. M. Olson (Eds.), What might have been: The social psychology of counterfactual thinking (pp. 199-231). Mahwah, NJ: Erlbaum.

Singer, J. A. (2004). Narrative identity and meaning making across the adult lifespan: An introduction. Journal of Personality, 72, 437-459.

Solomon, S., Greenberg, J., \& Pyszczynski, T. (1991). A terror management theory of social behavior: The psychological functions of selfesteem and cultural worldviews. In M. P. Zanna (Ed.), Advances in experimental social psychology (Vol. 24, pp. 93-159). San Diego, CA: Academic Press.

Summerville, A., \& Roese, N. J. (2008). Dare to compare: Fact-based versus simulation-based comparison in daily life. Journal of Experimental Social Psychology, 44, 664-671.

Taylor, S. E. (1983). Adjustment to threatening events: A theory of cognitive adaptation. American Psychologist, 38, 1161-1173.
Taylor, S. E. (1989). Positive illusions: Creative self-deception and the healthy mind. New York, NY: Basic Books.

Taylor, S. E., \& Brown, J. D. (1988). Illusion and well-being: A social psychological perspective on mental health. Psychological Bulletin, 103, 193-210.

Taylor, S. E., Kemeny, M. E., Reed, G. M., Bower, J. E., \& Gruenewald, T. L. (2000). Psychological resources, positive illusions, and health. American Psychologist, 55, 99-109.

Taylor, S. E., Lichtman, R. R., \& Wood, J. V. (1984). Attributions, beliefs about control, and adjustment to breast cancer. Journal of Personality and Social Psychology, 46, 489-502.

Tedeschi, R. G., \& Calhoun, L. G. (1996). The Posttraumatic Growth Inventory: Measuring the positive legacy of trauma. Journal of Trauma Stress, 9, 455-471.

Tetlock, P. E. (1998). Close-call counterfactuals and belief-system defenses: I was not almost wrong but I was almost right. Journal of Personality and Social Psychology, 75, 639-652.

Tetlock, P. E., \& Lebow, R. N. (2001). Poking counterfactual holes in covering laws: Cognitive styles and historical reasoning. American Political Science Review, 95, 829-843.

Thompson, C. P., Skowronski, J. J., Larsen, S. F., \& Betz, A. L. (Eds.). (1996). Autobiographical memory: Remembering what and remembering when. Mahwah, NJ: Erlbaum.

Tomkins, S. S. (1987). Script theory. In J. Aronoff, A. I. Rabin, \& R. A. Zucker (Eds.), The emergence of personality (pp. 147-216). New York, NY: Springer.

Trope, Y., \& Liberman, N. (2003). Temporal construal. Psychological Review, 110, 403-421.

Updegraff, J. A., Cohen Silver, R., \& Holman, E. A. (2008). Searching for and finding meaning in collective trauma: Results from a national longitudinal study of the 9/11 terrorist attacks. Journal of Personality and Social Psychology, 95, 709-722.

Watkins, E. R. (2008). Constructive and unconstructive repetitive thought Psychological Bulletin, 134, 163-206.

Wells, G. L., \& Gavanski, I. (1989). Mental simulation of causality. Journal of Personality and Social Psychology, 56, 161-169.

Whitson, J., \& Galinsky, A. (2008, October 3). Lacking control increases illusory pattern perception. Science, 322, 115-117.

Wilson, T. D., \& Gilbert, D. T. (2008). Explaining away: A model of affective adaptation. Perspectives on Psychological Science, 3, 370386.

Wilson, T. D., \& Kraft, D. (1993). Why do I love thee? Effects of repeated introspections on attitudes toward the relationship. Personality and Social Psychology Bulletin, 19, 409-418.

Wood, J. V., Taylor, S. E., \& Lichtman, R. R. (1985). Social comparison in adjustment to breast cancer. Journal of Personality and Social Psychology, 49, 1169-1183.

Young, M. J., \& Morris, M. W. (2004). Existential meanings and cultural models: The interplay of personal and supernatural agency in American and Hindu ways of responding to uncertainty. In J. Greenberg, S. L. Koole, \& T. Pyszczynski (Eds.), Handbook of experimental existential psychology (pp. 215-230). New York, NY: Guilford Press.

Zeelenberg, M., \& Pieters, R. (2007). A theory of regret regulation 1.0 Journal of Consumer Psychology, 17, 3-18.

Received February 26, 2009

Revision received June 4, 2009

Accepted June 7, 2009 